\title{
Social Informatics: Principles, Theory, and Practice
}

\author{
Steve Sawyer, Michael Tyworth \\ College of Information Sciences \& Technology \\ The Pennsylvania State University, USA, \\ sawyer@ist.psu.edu, mtyworth@ist.psu.edu
}

\begin{abstract}
Through this paper we make two contributions to social informatics: the interdisciplinary study of the design, development, uses and consequences of information and communication technologies that takes into account their interaction with institutional and cultural contexts. Our first contribution is to make a connection from social informatics to general principles of sociotechnical theories. We do this to both connect social informatics scholarship more directly to the large and growing literature(s) that engage socio-technical theorizing and to advance these principles more directly through social informatics. Our second contribution to social informatics is to engage two contemporary theoretical approaches that draw on social informatics principles: socio-technical interaction networks and principles of social actors and apply them to current practice. We do so to demonstrate that these analytic approaches are the needed tools to help scholars and reflective professionals in practice engage social informatics analyses. By doing this we highlight the potential of social informatics while honouring Rob Kling's legacy in helping to establish this transdiscipline.
\end{abstract}

Keywords: social informatics, socio-technical principles, social actors, sociotechnical interaction networks, integrated criminal justice information systems

\section{Introduction}

In this paper we advance the work of Rob Kling and in doing so continue the empirical, theoretical, and critical engagement of social informatics. By social informatics we mean "...the interdisciplinary study of the design uses and consequences of information technologies that takes into account their interaction with institutional and cultural contexts [Kling, 1999]." Through this paper we make two contributions to the ongoing efforts to engage social informatics principles, concepts and analyses. First, we make a direct connection between social informatics

Please use the following format when citing this chapter:

Sawyer, S., Tyworth, M., 2006, in IFIP International Federation for Information Processing, Volume 223, Social Informatics: An Information Society for All? In Remembrance of Rob Kling, eds. Berleur, J, Numinen, M. I., Impagliazzo, J., (Boston: Springer), pp. 49-62. 
and general principles of socio-technical theories. We do this to both connect social informatics scholarship more directly to the large and growing literature(s) that engage socio-technical theorizing and to advance these principles more directly through social informatics.

Our second contribution is to identify nascent theories that draw on social informatics principles. We do so because these theories present an opportunity for scholars and reflective professionals in practice engage social informatics analyses (e.g., Lamb and Sawyer, 2005). Pursuing this second contribution we contrast two emerging theories - socio-technical interaction networks (STIN) and social actor approaches - that reflect these socio-technical principles and build on social informatics. The STIN approach provides a system-level framework for analyzing socio-technical networks / systems that views the social and the technological as fundamentally inseparable components of the system [Kling, McKim, \& King, 2003]. The social actor approach models users as social beings, embedded within an enabling and constraining social context but with individual agency to shape that context [Lamb \& Kling, 2003]. Both the STIN and social actor approaches represent current theorizing activities within social informatics. In our study of integrated criminal justice systems (ICJS), we have found that these theoretical frameworks inform our understanding of design, deployment, and use of ICJS. More importantly, STIN and social actor theories point us to relevant issues in the design of technologically and socially complex interorganizational ICT.

This paper continues with a discussion of socio-technical principles. Building on this foundation we then tie the principles to both STIN models and social actor theory, followed by an application of those theories to the study of ICT in practice. We conclude by discussing future directions for social informatics research.

\section{Socio-technical Principles}

Social Informatics is grounded in the principles that guide socio-technical theory. We build here on Bijker's [1995] argument that socio-technical theories reflect four principles: (1) the seamless web, (2) the change and continuity, (3) the symmetry, and (4) action and structure. In doing this we note that in engaging these principles we are not engaging a particular theory: we are arguing that social informatics reflects principles seen as common to theories of socio-technical change and action.

The seamless web principle states that any socio-technical theory should not $a$ priori privilege the technological or material explanation ahead of the social or vice versa. In the parlance of academic disciplines, neither the computer science nor the sociology views should be privileged. In social informatics, we focus on the web of computing, treating the material artefacts and social practices as bound up together in situated and mutually-constituted activity.

The principle of change and continuity states that socio-technical theories must account for both change and stability and not one to the exclusion of the other. Socio-technical phenomena are at once both continuous and evolving, retaining an inherent structure while adapting over time $\mathrm{i}^{\mathrm{ii}}$. In social informatics, the temporal and 
historical trajectories of both human activity and technological development are intertwined and continuously evolving.

The principle of symmetry states that the successful working of technology must be viewed as a process rather than an end-state (this relates directly to the principle of change and continuity). Focusing on the workings of technology as a process rather than an end-state, avoids the trap of technologically deterministic analyses that are too often found in other perspectives. In social informatics, this principle also steers us towards engaging situated empirical studies as part of the research.

The principle of action and structure states that socio-technical theories should address both the agency of the social actor and the structural constraints. In this view, people have agency in shaping, changing, and enacting their social context and uses of ICT. But, they are also constrained by social institutions (Scott, 2001). In social informatics this steers scholars to focus on both the structural and agentic activities of both people and ICT.

The simply-stated (but difficult to engage conceptually or empirically) premise underlying these four socio-technical principles is that neither technology nor social context are isolated, isolatable, or unchanging. Instead the social contexts and technological artefacts are perpetually interacting and shaping each other.

\subsection{Socio-technical Principles and Social Informatics}

Some might see social informatics as a subset of socio-technical scholarship: one focused on particular forms of technology that directly engage information processing and communications technologies (ICT). This suggests that these ICT have particular characteristics that distinguish them from other forms of technology ${ }^{\text {iii }}$. That is, there must be particular characteristics that distinguish a computer and its applications from, say, a nuclear reactor, microscopes, or electrical power grids.

We argue that ICTs configurational nature is one distinguishing characteristic from other forms of technology. By configurational we mean that that in their design and use, ICT are interpretively flexible, multiply adaptive in use, and always evolving [Fleck, 1994; Quintas, 1994; Suchman, 1987, 2003]. Some may argue that these differential characteristics are but a matter of degree. We defer to other venues that discussion, and here claim that social informatics is premised on the study of ICT as a specific and volatile type of socio-technical ensemble.

The practice of social informatics is trans-disciplinary - spanning such diverse fields as computer science, sociology, communications, education, information systems, information science, and others. Social informatics is neither a theory nor a method: it is a perspective in the same way as are human-computer interaction and family studies. In action, social informatics is an approach to understanding, theorizing and engaging ICT that reflects five specific principles on social analysis of computing [Lamb and Sawyer, 2005]:

1. In social informatics ICT are seen as a socio-technical system: a web-like arrangement of the technological artefacts, people, and the social norms, practices, and rules. As a result, for the social informaticist the technological artefact and the social context are inseparable for the purposes of study and 
analysis [Kling, McKim, \& King, 2003]. It is this principle that most directly links to socio-technical principles.

2. Social-informatics is problem-oriented. This means that social informatics research focuses on the 'real-world' design, development, and use of ICT. The purpose of which is to inform the discourse on ICT to help individuals, organizations, and societies make better use of ICT. There is no correlate for this in the socio-technical principles.

3. The design, development and use of ICT are contextualised and sociallysituated. The social and historical contexts pervade every element of ICT from conceptualisation to design to implementation and use.

4. People are social actors [Lamb \& Kling, 2003]. People have individual motivations, interests, practices, values that influence how and why they use ICT. Though constrained and enabled by the social institutions in which they are embedded, people have individual agency that both shapes those institutions and influences their adoption and use of ICT.

5. The social informatics researcher adopts a critical orientation and prioritizes an empirical view of ICT. By 'critical orientation' we don not mean to convey synonymy with critical theory ands its orientation towards emancipation and Marxist theory [Orlikowski \& Baroudi, 1991]. Here, critical denotes an orientation that challenges the accepted wisdom and taken-for-granted assumptions regarding ICT. It is through this challenging of assumptions that the social informaticists avoid simplistic technological determinism and gain deeper insight into the complexity of ICT's design, development, deployment and ongoing uses.

Using these principles, social informatics researchers have over time consistently revealed in their empirical studies a number of consistent findings (See for example: Kling, Rosenbaum, \& Sawyer, 2005b). These common findings include:

1. The paradoxical effects of ICTs take up and uses,

2. That ICTs uses shape action and thoughts that benefit some over others,

3. That the design and implementation of ICTs have moral and ethical consequences, and

4. That the phenomenon of interest will vary with level of analysis

Given that these are so commonly found in empirical studies of computing's design, development, adoption and use, we argue that these are worthy to report, but do not constitute new insight. Indeed, the progress of social informatics must be based both on the constant presentation of these common findings and, more importantly, the additional detailing that reflects how these common findings are suppressed or magnified through particular actions, events or arrangements, the temporal sequencing of engagements, and the contextual differences (and measures) between better and worse computerization efforts. To do this, we and others have argued for analytic approaches that are grounded in social informatics principles [Horton, Davenport, \& Wood-Harper, 2005; Lamb \& Sawyer, 2005; Sawyer \& Crowston, 2004; Wood-Harper \& Wood, 2005]. 


\subsection{Socio-technical principles in theory}

For social informatics to continue expanding on its potential as an alternative and insightful approach to studying ICT, scholars in this area must capitalize on the empirical work done to date, and move into the realm of theorizing more specifically on the nature and roles of ICT. This does not mean we think the social informatics researcher should abandon the commitment to empirical work. Rather, we believe that development and refining of social informatics theories is tied to improved analytic approaches that will, in turn, better guide the empirical activities of social informatics research. And, in turn, this work will illuminate issues with the design, development, take up and uses of ICT that other approaches neglect or misrepresent. Improved analytical methods will be useful to practicing professionals, will be more useful in formal education of IT professionals, and will serve as a counterpoint to the unsupportable but comforting direct effects analytic approaches to understanding ICT [Kling, Rosenbaum, \& Sawyer, 2005b].

As noted earlier, there are number of viable and approaches to engaging social informatics analyses. For example, one approach is to continue incorporating and extending concepts and approaches from other domains [Orlikowski \& Barley, 2001]. Continuing to 'borrow' theories from other disciplines and apply them to ICT provides social informatics with an opportunity to continue demonstrating the value of social theories in the study of ICT.

A second approach is the development of 'native' social informatics theories, ones that arise from within the social informatics community. Social informatics scholars can produce and then demonstrate the utility of social informatics theory, and then 'export' those theories to other fields social informatics establishes itself as a reference discipline to others [Baskerville \& Myers, 2002] iv. By becoming a reference discipline, social informatics not only communicates its results to other researchers but also develops a more distinct identity. We see greater intellectual value in the development and refining of theories native to social informatics.

Theoretical development in social informatics has value beyond communicating the results of social informatics research to other scholars and establishing identity. The development of social informatics theory presents the opportunity for social informatics researchers to benefit people who use ICT through contributing to better designed ICT that accounts for the social and the technical.

\subsection{Socio-technical Interaction Networks}

Conceptually, a socio-technical network is a view of a system as a network of people and technologies which are inseparable when trying to examine and understand the system [Kling, McKim, \& King, 2003]. Socio-technical interaction network models (STINs) present a method for understanding the interactions between individual socio-technical networks (nodes) that comprise the socio-technical interaction networks [Kling, McKim, \& King, 2003]. This is accomplished through the mapping of relationships between people, people and technology, and technologies [Kling, McKim, \& King, 2003]. 
Four assumptions that echo both the socio-technical principles and social informatics bases serve as the foundation for STIN [Kling, McKim, \& King, 2003]:

- the social and technical are not meaningfully separable,

- social theories should influence design,

- system participants (people) are embedded in multiple social relationships,

- sustainability and routine are critical elements of design.

These assumptions are what separate STIN from those theories that focus on either the social or the technological to the exclusion of the other.

\subsection{Users as Social Actors}

Roberta Lamb and Rob Kling [Lamb \& Kling, 2003] published their theory of users as social actors as way of conceptualizing users of ICTs to get beyond the simple abstract models that populate much of the human-computer literature. Their conceptualization of the user is more socially-rich and situated. According to concept of a social actor, people are not simply users of ICT, but are socially-complex individuals who are engaging uses of ICT as members of one or more organizations that make use of ICTs to engage in mediated social interactions. Social actors are both enabled and constrained in their uses of ICTs by the social milieus in which they exist. The constraints of their social environment means that social actors are often limited in what they can do. However, social actors also have active agency in shaping these milieus. The degree to which structure and action are allowed are dependent in part on situated contexts and elements such as the task, roles, timing, nature of interdependencies, particular ICTs being used, and goals.

Lamb \& Kling [2003] identify four dimensions of the social actor: affiliations, environments, interactions, and identities. Affiliations are the social ties the social actor maintains - for example professional networks - and occur both within and across organizational boundaries. Environments represent the normative, regulatory, and cognitive institutions that both enable and constrain social actors use of ICTs. Interactions are the information, modes of communication, and resources employed by social actors as they socially engage with other members of the organization or other organizations. Identities comprise both the identity articulated by the social actor as well as the identity of the social actor articulated by the organization. These four dimensions are not entirely discrete; rather there is some overlap between dimensions. In fact it is the way in which the theoretical dimensions of the social actor overlap that gives it much of its power.

\section{Empirical Work}

As an empirical base to support our comparison of these two theories, we draw on our ongoing work in the development and uses of ICJS. We see ICJS as one area that presents a significant opportunity for social informaticists to both develop theory and contribute to practice. E-Government, or digital governance, is both an emerging area of scholarship and a fast evolving phenomenon in society. This is particularly true for issues of law enforcement and national defense where there is increasing 
pressure to computerize or modernize existing ICT given the recent attention to international terrorism [National Commission on Terrorist Attacks upon the United States, 2004]. And, for the United States at least, it may be that there is no other area where the consequences of adhering to the deterministic view of ICT are as potentially catastrophic. Simply, and in spite of these risks and evidence against such a view, the deterministic model continues to be advocated.

For example, in his article on improving intelligence analyzing systems Strickland [Strickland, 2004] focused exclusively on technological change as the solution to the problems of information sharing among agencies. For example, he identifies data disintegration, problems in analytical methodology, and technological obsolescence as the primary areas of concern. Yet, as Richard Shelby [Shelby, 2002] noted in his addendum to the Senate Select Committee investigating pre- and post9/11 intelligence:

The CIA's chronic failure, before September 11, to share with other agencies the names of known Al-Qa'ida terrorists who it knew to be in the country allowed at least two such terrorists the opportunity to live, move, and prepare for the attacks without hindrance from the very federal officials whose job it is to find them. Sadly, the CIA seems to have concluded that the maintenance of its information monopoly was more important that stopping terrorists from entering or operating within the United States.

Though Senator Shelby's language is polemic, the message is clear: without significant changes to organizational norms of action, simply implementing new technological systems or updating existing ones will in many instances fail to achieve policy goals. It is exactly this type of problem for which social informatics is particularly applicable.

An e-Government policy area directly related to the issue of intelligence sharing is the problem of integrating information systems among law enforcement and criminal justice agencies. Prior to, but especially after $9 / 11$, there has been a significant movement within government to integrate ICT across law enforcement and criminal justice agency boundaries in order to facilitate cross-agency communication and information sharing [See for example: General Accountability Office, 2003].

Criminal justice information systems have historically been developed in an ad hoc manner, tailored to the needs of the particular agency, and with minimal support resources (either fiscal or expertise) [Dunworth, 2000, 2005; Sawyer, Tapia, Pesheck, \& Davenport, 2004]. As a result federal and state governments have begun the process of trying to develop and implement integrated criminal justice systems that allow agencies to share information across organizational boundaries. Examples of such systems are Pennsylvania's Justice Network (JNET), the Washington D.C. metro area's Capital Wireless Integration Network (CapWIN), and the San Diego region's Automated Regional Justice Information System (ARJIS) among others.

We find ICJSs to be ideal opportunities to conduct social informatics research for three reasons. First, law enforcement is a socially complex domain comprised of and embedded in multiple social institutions [Sawyer, Tapia, Pesheck, \& Davenport, 2004]. Such institutions include organizational practice and culture, societal norms and values, and regulatory requirements. Second, law enforcement agencies have 
long been adopters of ICT to the point where ICT are now so ubiquitous that they are viewed as integral to policing [Hoey, 1998]. This remains true in spite of a decidedly mixed record of success [Baird \& Barksdale, 2003; Bureau of Justice Assistance, 2002]. Third, the historical practice of ad hoc and siloed systems development suggests that law enforcement is an area where new systems development approaches are needed.

\subsection{Automated Regional Justice Information System (ARJIS)}

Currently we are completing a case study of the ARJIS system in San Diego, California. The Automated Regional Justice Information System (ARJIS) of San Diego, California is one of the pre-eminent criminal justice information systems initiatives in the United States. Initially a mainframe records management system accessible by multiple jurisdictions in the San Diego area, ARJIS has evolved over the past 20 years both organizationally and technologically. Organizationally ARJIS has become its own organization embedded in the county government structure. Technologically ARJIS is in the process of developing wireless communications systems, global query application, and public safety cable television channel.

We used five forms of data collection. Three focus on gathering primary data: interviews (face-to-face, by phone, and via email, depending on the point of the interaction), ride-alongs with - and other direct observation of - users. We also gathered secondary documents such as reports, memos and locally-relevant material (we, of course, have done and continue to do extensive web and library research to support the field work) as well as data about device uses, data transmission, and ARJIS usage via unobtrusive means (such browser logs, server logs, and telecom activity logs).

Data from the sources are transcribed into digital format or collected at source in digital format. Data from the usage logs came in digital format. This supports our analysis across different data sets and data collection approaches. To do this analysis we are using traditional qualitative/case study data analysis approaches [See: Miles \& Huberman, 1984]. In particular, we draw on three techniques: (1) interim analysis of the data to guide data collection and interpretation in the future, (2) explanatory event matrices, and (3) content analysis of the interview/focus group transcripts and field notes. When the study is complete we expect to have more than fifteen interviews (of from one-to-two hours duration, each), notes and details from six officer ride-alongs, and over 650 pages of documents.

\subsection{Socio-technical principles and Social Informatics theory reflected in practice}

Preliminary analysis of our case study data indicates the ARJIS system is very much a socio-technical network as theorized by Kling et al. [2003]. ARJIS is both a governmental agency and a technological infrastructure, and both are highly intertwined. To understand the design and evolution of the ARJIS system, one must understand the design and evolution of the organization, and vice versa. We find 
support here for the seamless web principle (that both the technical and the social have equal standing). This is reflected in the STIN principle of the inseparability of the technical and social and the social actors principle of use in context.

\begin{tabular}{|c|c|c|c|}
\hline $\begin{array}{c}\text { Socio-technical } \\
\text { Principle }\end{array}$ & STIN & Social Actor & ARJIS \\
\hline \multirow[t]{2}{*}{ Seamless Web } & $\begin{array}{l}\text { Social and technical } \\
\text { not meaningfully } \\
\text { separable }\end{array}$ & $\begin{array}{l}\text { Use is socially } \\
\text { contextual and role } \\
\text { specific }\end{array}$ & $\begin{array}{l}\text { Embedded in } \\
\text { governmental and } \\
\text { technological } \\
\text { infrastructures. }\end{array}$ \\
\hline & & & $\begin{array}{l}\text { Contextual setting of } \\
\text { use greatly shapes } \\
\text { user behavior. }\end{array}$ \\
\hline $\begin{array}{l}\text { Change and } \\
\text { Continuity }\end{array}$ & $\begin{array}{l}\text { Sustainability and } \\
\text { routine are critical } \\
\text { elements of system } \\
\text { design }\end{array}$ & Design in use & $\begin{array}{l}\text { ARJIS is tied to } \\
\text { existing } \\
\text { technological } \\
\text { systems, government } \\
\text { agencies which both } \\
\text { constrain and enable } \\
\text { system and agency } \\
\text { design. }\end{array}$ \\
\hline Symmetry & $\begin{array}{l}\text { System participants } \\
\text { are embedded in } \\
\text { multiple social } \\
\text { relationships }\end{array}$ & $\begin{array}{l}\text { Relationships are } \\
\text { dynamic, multilevel, } \\
\text { multivalent, and } \\
\text { multi-network }\end{array}$ & $\begin{array}{l}\text { ARJIS designers and } \\
\text { managers engage } \\
\text { multiple } \\
\text { relationships both } \\
\text { vertically and } \\
\text { horizontally. }\end{array}$ \\
\hline \multirow[t]{2}{*}{ Action and Structure } & $\begin{array}{l}\text { The ways in which } \\
\text { STIN evolve is } \\
\text { through both } \\
\text { structural adherence } \\
\text { and agentic actions. }\end{array}$ & $\begin{array}{l}\text { People's actions are } \\
\text { guided by existing } \\
\text { structures, but they } \\
\text { retain some amount } \\
\text { of agency }\end{array}$ & $\begin{array}{l}\text { ARJIS management } \\
\text { and designers are } \\
\text { subject to historical } \\
\text { institutional } \\
\text { pressures. }\end{array}$ \\
\hline & & & $\begin{array}{l}\text { ARJIS leaders act as } \\
\text { brokers among and } \\
\text { between individual } \\
\text { agencies. They seek } \\
\text { to find commonality } \\
\text { across individual } \\
\text { normative systems. }\end{array}$ \\
\hline
\end{tabular}

Table 1 - Social Informatics Principles, Theories, and Practice - ARJIS

The technological system has been developed in conjunction with the establishment of ARJIS as an independent Joint Powers Agency. As such, individual design decisions are fundamentally linked to the manner in which the ARJIS organization has been established and embedded in the existing government structure. Similarly, we found that use of the system was very specific to the context the social actor was engaged in because context had great influence on the actions 
available to the actor. This dual nature of ARJIS reflects the socio-technical principle of a seamless web.

The principle of change and continuity stipulates that both system stability and evolution must be accounted for. STIN theory reflects this as sustainability and routine as key to system design. Social actor theory refers this to 'design in use,' or the phenomenon of actors in effect changing the ICT through use in unanticipated ways. ARJIS current design plan consists of maintaining the legacy system while developing a parallel system to incorporate new applications and technology is an example of the principle of change and continuity. Similarly the emergent nature of the parallel system allows for on-the-go design decisions as long as they are consistent with the overall development plan. We observed design in use in the use of the wireless handheld system. In experimenting with the handhelds, agents discovered they could take photographs and record sound with the devices and incorporated those uses into their investigatory practices. The critical point here is that the design of ARJIS is not static, either in development or after deployment; but continues to be adjusted both in development and use.

The principle of symmetry views the successful working of ICT as a process not an end-state. This reflects the ongoing evolutionary nature of ICT. STIN theory articulates this principle as participants embedded in multiple social relationships that shape their participation in the network and result in a constantly evolving network. Social actors present the user in a similar manner: as embedded in dynamic, multilevel, multivalent and multi-network relationships. ARJIS managers have relations with policymakers, users, developers, and vendors, among many others. These relationships have had and continue to have a direct impact on the how they approach the development of ARJIS. For example, the costly failed attempt to comprehensively upgrade the original ARJIS system through a private vendor continues a decade ago continues to drive ARJIS' focus on incremental but focused initiatives that can demonstrate a return on investment.

The principle of action and structure reflects the role of structure and individual agency in shaping design and use. Social actor theory articulates this principle as the environments the actor is embedded in, the affiliations of the actor and organization, and the interactions available to the actor. The organization of ARJIS is embedded in the larger institutions of local, regional, state, and federal governance as well as cultural, technological, and economic institutions. Norms in those institutions directly shape ARJIS management and design decisions. ARJIS also has agency and exercises this agency through guiding the ARJIS agenda and acting as a broker between individual agencies, policymakers, etc. ARJIS management and designers network nationally, helping to shape national integration initiatives such as data standards. Similarly, ARJIS mandates the regional data standards and ensures compliance by requiring it for participation.

In our observations of users we also found that institutional and technological structure played a large role in their use of the ARJIS system. For example, we found that officers from one agency rarely used the ARJIS system as part of their normal routines. They felt the functionality of the ARJIS system was not consistent with their objectives as patrol officers; the organizational culture was not oriented towards extensive use of ARJIS by patrol officers, and technological limitations such as access problems made using ARJIS prohibitive in comparison to competing systems. 
In contrast, agents in the federal agency we observed used ARJIS extensively viewing the system as a better resource than other agency resources such as dispatch which often had long response delays and was resource limited.

\section{Discussion}

Drawing from the ongoing work in ARJIS, as briefly outlined in the previous section, in comparing STIN and social actor approaches we make note that these models have different foci and lead to different insights. Both the STIN and social actor approaches reflect the principles of socio-technical theories and engage social informatics principles. Yet, in the STIN, the attention is directed towards the ways in which the technological elements are embedded into the large socio-historical context. This ensemble approach steers attention to the shape of the network in which the particular technological elements are embedded. In contrast, the social actor approach focuses attention towards the ways in which people negotiate among the structural and agentic forces, with the ICT serving as elements of both. The social actor model engages the processes of action more directly, while the STIN engages the structure of the socio-technical network of arrangements.

The differential foci of these two approaches lead to different insights. STIN analyses highlight the structural engagement of the technological artefacts with the socio-historical environment. And, in the context of ARJIS, illuminate the ways in which the RJIS functionality is both shaped and embedded in the larger and smaller scale institutional trajectories. Conversely, the social actor approach points our attention to the actions of the ARJIS leadership, the officers using the systems, and the political pressures both face in negotiating development and use of these technologies.

What does this say about social informatics? First, in contrasting STIN with the social actor perspective we note that these differing approaches to engaging the principles of socio-technical theorizing support the contention that social informatics is not a singular theory, but rather an analytic perspective and set of principles. The social informatics lens is neither monocular, nor rigidly focused on one set of activities and issues. The STIN and social actor approaches help to illustrate the intellectual opportunity to develop analytic models that reflect socio-technical principles as they apply to ICT.

We further note that the treatment of ICT demands additional attention. Both the STIN and social actor model engage ICT but struggle with how best to represent the particular technological features, functions and behaviors that these systems allow, support, and defer. The configurational and interpretive nature of ICT suggests that practice-based approaches (See for example: Orlikowski, 1992; Orlikowski, Yates, Okamura, \& Fujimoto, 1995) are likely to be fruitful vehicles to developing this added conceptual and empirical depth to social informatics depictions of the design, development and uses of computing. 


\section{References}

Baird, Z., \& Barksdale, J. (2003). Creating a Trusted Network for Homeland Security: Second Report of the Markle Foundation Task Force. Task Force on National Security in the Information Age Retrieved January 1, 2005, from http://www.markle.org/downloadable_assets/nstf_report2_full_report.pdf

Baskerville, R., \& Myers, M. (2002). Information systems as a reference discipline. MIS Quarterly, 26(1), 1-23.

Bijker, W. E. (1995). Of Bicycles, Bakelites, and Bulbs : Toward a Theory of Sociotechnical Change. Cambridge, MA: MIT Press.

Bureau of Justice Assistance. (2002). Mission Possible: Strong Governance Structures for the Integration of Justice Information Systems. Retrieved November 3, 2004. from http://www.ncjrs.org/pdffilesl/bja/192278.pdf.

Dunworth, T. (2000). Criminal Justice and the IT Revolution. Policies, Processes, and Decisions of the Criminal Justice System, 3, 371-426.

Dunworth, T. (2005). Information Technology and the Criminal Justice System: A Historical Review. In A. Pattavina (Ed.), Information Technology and the Criminal Justice System (pp. 1-28). Thousand Oaks, CA: Sage Publications, Inc.

Fleck, J. (1994). Learning by trying: the implementation of configurational technology. Research Policy, 23(6), 637-652.

General Accountability Office. (2003). Information Technology: FBI Needs an Enterprise Architecture to Guide Its Modernization Activities. Retrieved, from $\mathrm{http}: / / \mathrm{www}$. gao.gov/new.items/d03959.pdf.

Hoey, A. (1998). Techno-Cops: Information Technology and Law Enforcement. International Journal of Law and Information Technology, 6(1), 69-90.

Horton, K., Davenport, E., \& Wood-Harper, T. (2005). Exploring sociotechnical interaction with Rob Kling: Five 'big' ideas. Information Technology \& People, 18(1), 50-65.

Kitcher, P. (1982). Believing what we cannot prove. In P. Kitcher (Ed.), Abusing Science: The case against creationism (pp. 30-54). Cambridge, Mass.: MIT Press.

Kling, R. (1999). What is Social Informatics and Why Does it Matter? D-Lib Magazine Retrieved September 1, 2004, from http://www.dlib.org/dlib/january99/kling/0lkling.html

Kling, R., McKim, G., \& King, A. (2003). A Bit More to IT: Scholarly Communication Forums as Socio-Technical Interaction Networks. Journal of the American Society for Information Science and Technology, 54(1), 47-67.

Kling, R., Rosenbaum, H., \& Sawyer, S. (2005a). Teaching Key Ideas of Social Informatics. In Understanding and Communicating Social Informatics: A Framework for Studying and Teaching the Human Contexts of Information and Communications Technologies (pp. 83103). Medford, N.J.: Information Today Inc.

Kling, R., Rosenbaum, H., \& Sawyer, S. (2005b). Understanding and Communicating Social Informatics: A Framework for Studying and Teaching the Human Contexts of Information and Communications Technologies. Medford, New Jersey: Information Today, Inc.

Lamb, R., \& Kling, R. (2003). Reconceptualizing users as social actors in information systems research. MIS Quarterly, 27(2), 197-235.

Lamb, R., \& Sawyer, S. (2005). On extending social informatics from a rich legacy of networks and conceptual resources. Information Technology \& People, 18(1), 9-19. 
Miles, M., \& Huberman, A. (1984). Qualitative data analysis : a sourcebook of new methods. Newbury Park: Sage Publications.

National Commission on Terrorist Attacks upon the United States. (2004). The 9/11 Commission report: final report of the National Commission on Terrorist Attacks upon the United States : official government edition. Washington, D.C.: U.S. Government Printing Office.

Orlikowski, W. (1992). The Duality of Technology: Rethinking the Concept of Technology in Organizations, Organization Science, 3(4), 380-398.

Orlikowski, W., \& Barley, S. (2001). Technology and institutions: What can research on information technology and research on organizations learn from each other? MIS Quarterly, 25(2), 145-164.

Orlikowski, W. J., \& Baroudi, J. J. (1991). Studying Information Technology in Organizations: Research Approaches and Assumptions, Information Systems Research, 2(1), $1-19$.

Orlikowski, W. J., Yates, J., Okamura, K., \& Fujimoto, M. (1995). Shaping electronic communication: The metastructuring of technology in the context of use. Organization Science, 6(4), 401-423.

Quintas, P. (1994). Programmed Innovation? Trajectories of Change in Software Development. Information Technology \& People, 7, 25-47.

Sawyer, S., \& Crowston, K. (2004). Information Systems in Organizations and Society: Speculating on the Next 25 Years of Research. In B. Kaplan, D. Truex, D. Wastell, A. Wood-Harper \& J. DeGross (Eds.), Information systems research: relevant theory and informed practice, (pp. 35-52) Boston: Kluwer Academic Publishers.

Sawyer, S., Tapia, A., Pesheck, L., \& Davenport, J. (2004). Mobility and the First Responder. Communications of the $A C M, 47(3), 62-66$.

Scott, W. R. (2001). Institutions and organizations (2nd). Thousand Oaks, CA: Sage Publications.

Shelby, R. (2002). September 11 and the Imperative of Reform in the U.S. Intelligence Community: Additional Views of Senator Richard C. Shelby Vice Chairman, Senate Select Committee on Intelligence. Retrieved November 1, 2004. from http://www.fas.org/irp/congress/2002_rpt/shelby.pdf.

Strickland, L. (2004). Analytic Myopia, Data Disintegration and Homeland Insecurity. Bulletin of the American Society for Information Science and Technology, 30(6), 7-21.

Suchman, L. (1987). Plans and situated actions : the problem of human-machine communication. Cambridge: Cambridge University Press.

Suchman, L. (2003). Figuring Service in Discourses of ICT: The Case of Software Agents. In E. Wynn, E. Whitley, M. Myers \& J. DeGross (Eds.), Global and organizational discourse about information technology, (pp. 33-45). Boston: Kluwer Academic Publishers.

Winner, L. (1986). Do Artifacts Have Politics? In The Whale and the Reactor : A Search for Limits in an Age of High Technology (pp. 19-39). Chicago: University of Chicago Press.

Wood-Harper, T., \& Wood, B. (2005). Multiview as social informatics in action: past, present and future. Information Technology \& People, 18(1), 21-26.

Ziman, J. M. (1968). What is Science? In J. M. Ziman (Ed.), Public Knowledge: An Essay Concerning the Social Dimension of Science (pp. 5-27). London: Cambridge University Press. 


\section{Endnotes}

i We further note that these two models reflect a convenience sampling of available approaches to theorizing in social informatics. The intent here is not to review this large and growing collection, rather to highlight the intellectual insight and analytic opportunities that contemporary social informatics scholarship provides.

ii To continue with the evolution analogy, the penguin evolved over time to become a flightless bird covered in thick feathers to insulate it from extreme cold and the ability to swim underwater with great dexterity. Even with these adaptations, the penguin retains the fundamental structure of a bird in that it has wings, a beak, lays eggs, etc. Similarly the socio-technical system, for example the personal computer, retains fundamental components such as the processor, RAM, and monitor, while evolving in its design, configuration, and use (for example as a game platform or a word processor).

iii It may also be that the difference reflects more academic field differences than phenomenological. As philosophers of science and technology note, these field differences, while socially constructed, serve as boundaries in the practice of science (Kitcher, 1982; Winner, 1986; Ziman, 1968).

iv We realize that in practice one discipline does not truly export a theory to another, rather the latter imports from the former. We use the term export to denote the net effect of the adoption of a theory from one discipline by another. 